\title{
The Numerical Simulation of FOPS and ROPS Tests using LS-DYNA
}

\author{
G. KOKOT*, W. OGIERMAN** \\ *Silesian University of Technology, ul. Konarskiego 18A, 44-100 Gliwice, Poland, E-mail: grzegorz.kokot@polsl.pl \\ **Silesian University of Technology, ul. Konarskiego 18A, 44-100 Gliwice, Poland, E-mail: witold.ogierman@polsl.pl \\ cross ref http://dx.doi.org/10.5755/j01.mech.25.5.4314
}

\section{Introduction}

There is a large class of machines designed to work in a dangerous environment where falling down objects or rolling-over accidents often happen. This type of earth moving machines are mainly for the construction, forestry or mining industry. Bearing in mind the dangerous work conditions the operator security is one of the crucial problems in the designing process. Special attention is given to proper designing of an operator protective structure.

The protective structure of the earth-moving machinery is the area of a machine body that surrounds the passenger space and is strengthened or stiffened to provide extra protection for operators. As the protective structure shall absorb the energy of an impact, they are designed to remain rigid and not crush within safety operator area called deflection limiting volume (DLV) [1]. Protective structures called sometimes safety cages are usually pillars, a frame of a roof and a floor pan which form a cage like a structure. Protective structures of exemplary earth-moving machinery are presented in Fig. 1. They should protect the operator in the case of a falling down object or roll-over situation and secure the safe envelope space/operator compartment.

During the designing process of earth-moving machinery appropriate code requirements must be taken into account. The early stage of designing can be aided by numerical simulations of structure behaviour. It helps to avoid the wrong design and helps in fast searching for an optimal solution. This paper presents numerical simulations of tests that must be met according to ISO codes. The first one is the Falling Object Protective Structure test (FOPS - ISO 3449, EN 13627:2002) [2] which is appropriate for structures that are exposed to falling down object. The second one is the Rollover Protective Structure test (ROPS - ISO 3471, EN 13510:2004) [3]. ROPS structures main purpose is to provide the operator protection in the event of a machine rollover.
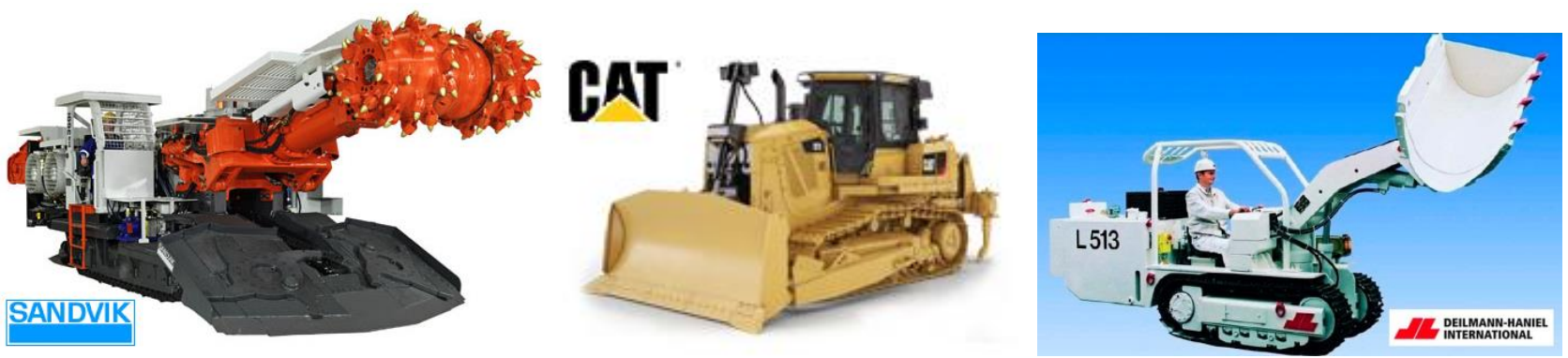

Fig. 1 Protective structures of Sandvik, CAT and Deilmann-Haniel earth-moving machinery

It is clearly stated that in order to certify protective structures for use, tests described in mentioned codes have to be carried out. All of the tests are destructive which means that in a case of a negative result they have to be carried out again on a new prototype, causing additional costs and extend the implementation time of the new machine. This can be avoided by using advanced numerical simulations based on the finite element method [4]. Numerical simulations of tests required by codes allow to avoid high cost and technical problems with experiments. Moreover, numerical simulations, mainly at the stage of virtual prototyping, allow to design energy absorbing structure properly and allow to avoid oversizing during optimization processes of the designed structure. In the next paragraphs discrete models, boundary conditions, loads, material taken into account and obtained results of suggested methodology are presented. There are a few computers aided engineering (CAE) systems for solving those types of problems (LS-DYNA, PAM CRASH, MSC. DYTRAN). They are widely used in solving the transient dynamic problems such as crush tests, bird-engine strikes, impact tests etc. [5-8]. For the purpose of this study the LS-DYNA software has been used. The paper is divided into two parts. The first concerns the procedure for FOPS test and the second concerns ROPS test.

\section{FOPS test simulation}

\subsection{Test overview}

Falling object protective structure is the system of structural members arranged in such a way to provide operators with reasonable protection from falling objects [2]. The FOPS test describes the structure resistance to falling objects. According to code, the weight is let free fall onto the cab ceiling from a definite height. The weight is made of steel or cast steel with a cylindrical or spherical shape. The height of free fall in correlation with the mass of the weight has to provide the impact energy of $1365 \mathrm{~J}$ for level I or the impact energy of $11600 \mathrm{~J}$ for level II. Levels of energy depend on purpose of the structure. For example, machines used in operations such as highway maintenance, landscaping and other construction site services belong to 
level I, machines used in mining, forestry belong to level II. An important element of the study is deflection-limiting volume (DLV) which represents residual space. Deflection limiting volume is defined as a space of orthogonal approximation of a large male, seated operator wearing normal clothing and a hard hat. Details and dimensions of DLV are prescribed in ISO 3164 [1] and partially presented in Fig. 2. Referring to the code after the test safety zone shall not be entered into by any part of the protective structure under the first or subsequent impact of the drop test object. When the drop test object penetrates the FOPS, it shall be considered to have failed that test. It means that the structure meets safety requirements if the impact does not puncture the roof and does not cause both elastic and plastic deformations in a way that violates the DLV. Besides the cab, structural parts that provide additional vertical stiffness should be included into test. Therefore, a piece of machine's frame that is directly connected with cabin, has been modelled in the finite element modelling phase.
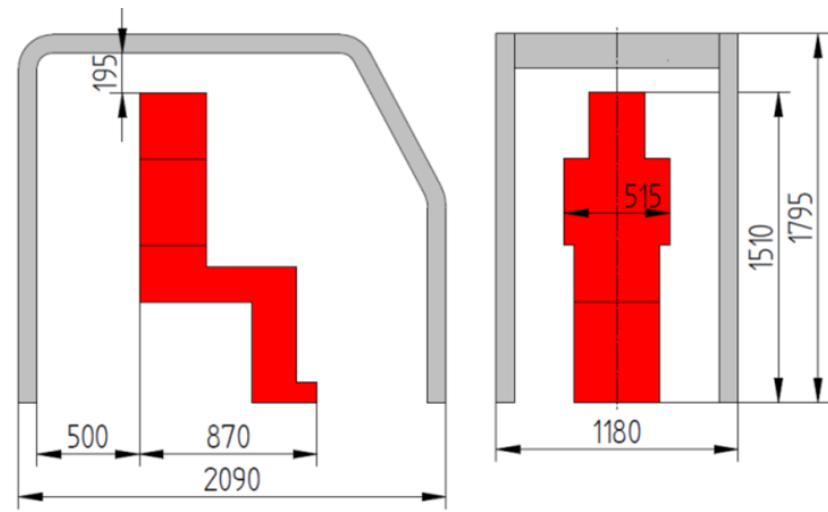

Fig. 2 Overall dimensions of the structure and DLV

\subsection{Numerical procedures}

Explicit time integration procedure was used during this study. Particularly a central difference method was applied [9]. In this method velocities and accelerations are expressed by Eqs. $(1,2)$. In this case velocities and accelerations are expressed only by displacements. Eq. (3) is obtained by substituting accelerations and velocities from classical matrix equation of motion by Eqs. (1) and (2). This is a governing equation of a central difference method. Using lumped mass and neglecting damping, displacements at time $t+\Delta t$ can be obtained without any matrix inversion. This approach is simple and very effective at handling nonlinearities. The explicit integration is a default time integration scheme implemented in LS-DYNA code [10].

$$
\begin{aligned}
& \dot{Q}_{t}=\frac{1}{2 \Delta t}\left(Q_{t+\Delta t}-Q_{t-\Delta t}\right), \\
& \ddot{Q}_{t}=\frac{1}{\Delta t^{2}}\left(Q_{t+\Delta t}-2 Q_{t}+Q_{t-\Delta t}\right), \\
& M Q_{t+\Delta t}=\Delta t^{2} F_{t}-\left(\Delta t^{2} K-2 M\right) Q_{t}-(M) \cdot Q_{t-\Delta t},
\end{aligned}
$$

where: $M$ and $K$ are mass and stiffness matrixes, $\ddot{Q}, \dot{Q}, Q$ are acceleration, velocity and displacement vector respectively, $F$ is external forces vector and $\Delta t$ is time step.
On the other hand, central difference method has a major drawback. For stability and accuracy, the required time step size is very small. To ensure integration scheme stability time step size should not exceed maximum value. The maximum time step can be calculated by using Courant criterion [8]:

$$
\Delta t_{\text {max }} \cong \frac{l}{c} \cong l \sqrt{\frac{\rho}{E}},
$$

where: $l$ is the shortest finite element edge in the whole grid, $c$ is speed of sound, $E$ is Young modulus and $\rho$ is density.

The protective structure is discretized by quadrilateral, four node shell elements with Belytschko-Tsay formulation [10]. This formulation provides high performance of computing; the number of integration points is reduced to one. To model properly nonlinear behaviour of material, five integration points through the element thickness were applied [11]. The finite element mesh of the analysed structure is presented in the Figs. 3,4.

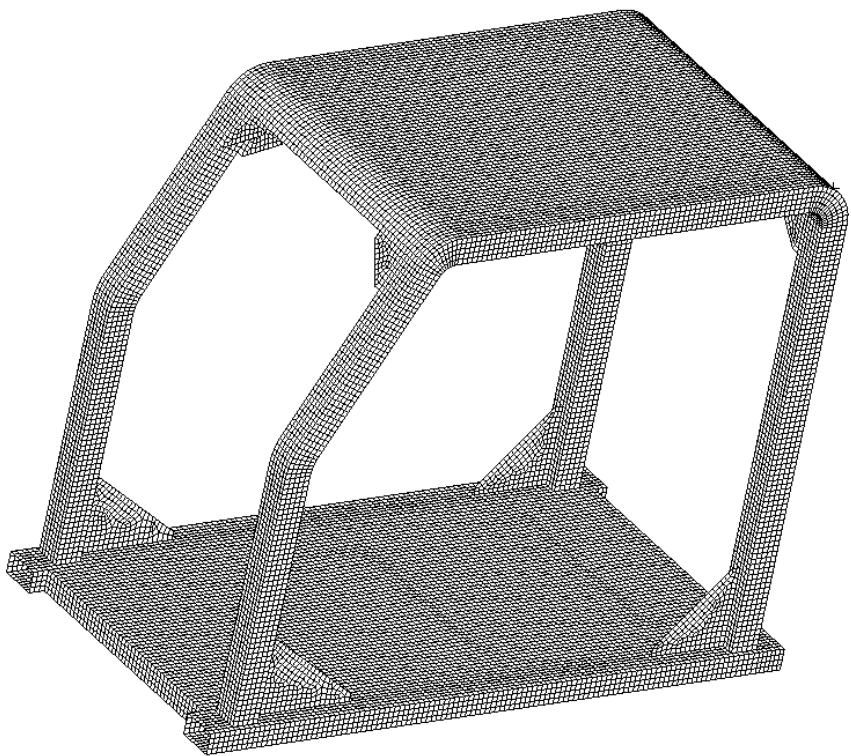

Fig. 3 Finite element mesh

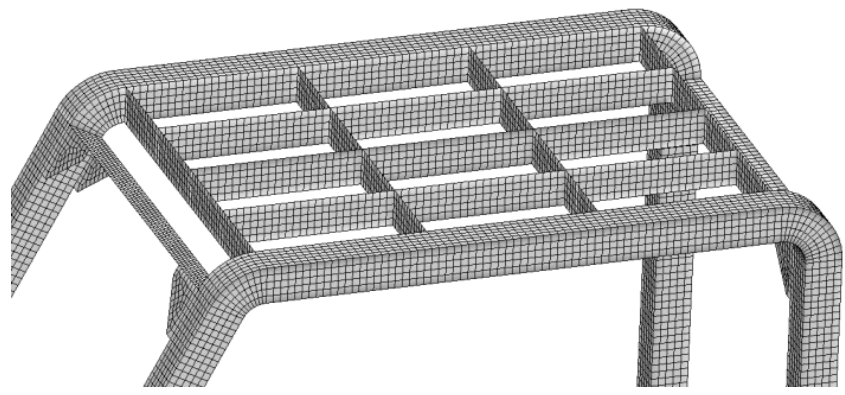

Fig. 4 Finite element mesh with section view on the internal part

Falling weight is discretized by hexagonal eight node elements (Fig. 5). Geometry of falling weight was considered in accordance with ISO code [2]. Mass of falling object equals $311.4 \mathrm{~kg}$. To decrease the time of computation, analysis of weight's free fall wasn't included. Analysis was started from the state when weight hit the cab's celling. As the initial condition, initial velocity of weight that provides the right impact energy was taken into account $(11.6 \mathrm{~kJ})$, 
particularly initial velocity of weight equals $8.63 \mathrm{~m} / \mathrm{s}$. The contact condition between the structure and the weight was applied. In addition, self-contact between structure's elements was set up. Model has been constrained in accordance with test conditions.

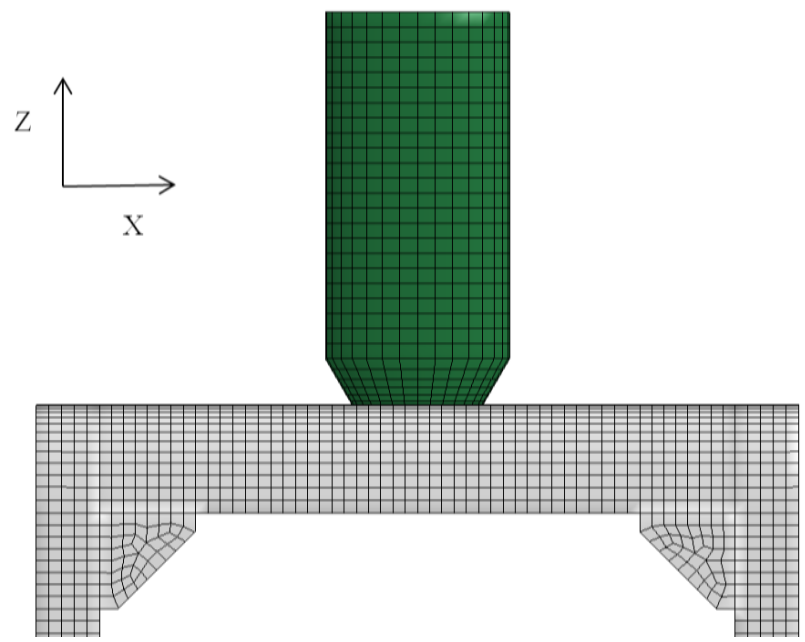

Fig. 5 Falling object in contact with cab's ceiling

\subsection{Material model}

A significant stage of building the numerical model is to set up an appropriate material model which has to simulate a real behaviour of the material. During this research the bilinear elastic-plastic material model was defined. Specifically, it was implemented as plastic-kinematic material model from LS-DYNA material models library [10, 11]. Strain rate is accounted for using Cowper-Symonds model [12] which scales the yield stress by the strain dependent factor (Eq. (5)). Mixed, isotropic-kinematic hardening was taken into consideration. Mentioned material model takes into account failure of the structure, finite elements that reach peak strain value are deleted from computation in particular time step.

$$
\sigma=\left[1+\left(\frac{\dot{\varepsilon}}{C}\right)^{\frac{1}{p}}\right]\left(\sigma_{0}+\beta E_{p} \varepsilon_{e f}\right)
$$

where: $\sigma$ is yield stress, $\dot{\varepsilon}$ is strain rate, $\sigma_{0}$ is initial yield stress, $C$ and $p$ are Cowper-Symonds strain rate parameters, $\beta$ is hardening parameter $(0-$ isotropic hardening, $1-$ kinematic hardening) $E_{p}=\frac{E_{\text {tan }} E}{E-E_{\text {tan }}}, E_{\text {tan }}$ is tangent modulus, $E$ is Young modulus, $\varepsilon_{e f}$ is effective plastic strain.

The other way is to use the Johnson-Cook model [13]:

$$
\sigma=\sigma_{0}\left[1+\left(\frac{1}{p}\right) \ln \left(\max \left(\frac{\dot{\varepsilon}}{D}, 1\right)\right)\right]
$$

where: $\sigma_{o}$ is initial static yield stress, $P$ and $D$ are material constants.

In the presented simulation the Cowper-Symonds model was used. Table 1 presents properties of material used in simulations.
Table 1

Material properties

\begin{tabular}{|l|l|}
\hline Density, $\mathrm{kg} / \mathrm{m}^{3}$ & 7860 \\
\hline Young modulus, $\mathrm{GPa}$ & 205 \\
\hline Poisson ratio & 0.3 \\
\hline Yield stress, $\mathrm{MPa}$ & 355 \\
\hline Tangent modulus, $\mathrm{MPa}$ & 763 \\
\hline Hardening parameter $\beta$ & 0.5 \\
\hline Strain rate parameter $\mathrm{C}, \mathrm{s}^{-1}$ & 40 \\
\hline Strain rate parameter $\mathrm{p}$ & 5 \\
\hline Failure strain $\varepsilon_{f}$ & 0.7 \\
\hline
\end{tabular}

\subsection{Simulation results}

As the results of numerical simulation the distribution of displacements and stresses can be plotted in the form of coloured maps. It is helpful in detailed analysis of the effort state. Displacement field connected with the largest deformation is shown in Fig. 6.

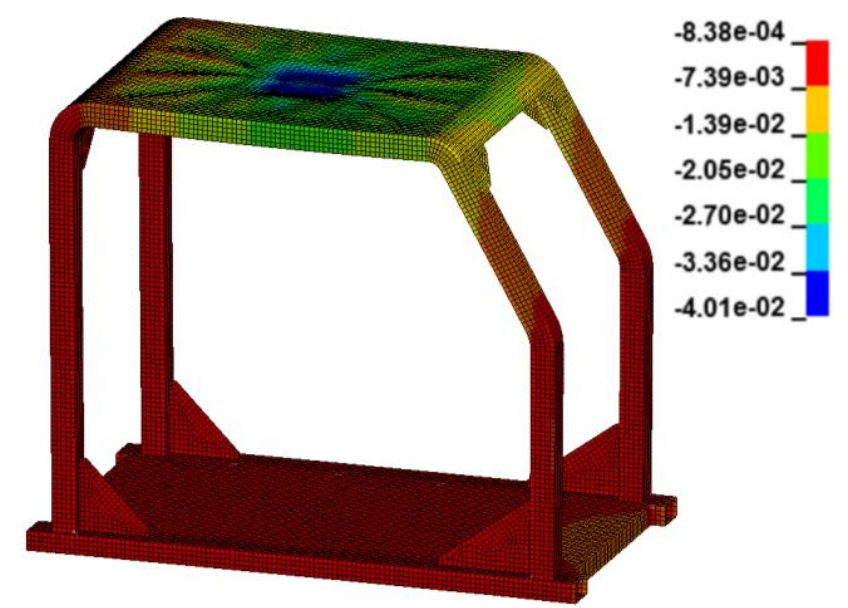

Fig. 6 Displacement field at time 0.0135 s, m

The displacements of characteristic nodes in $\mathrm{Z} \mathrm{di-}$ rection are presented in Fig. 7. Characteristic nodes are connected with that part of cab's ceiling that probably may eventually violate DLV. However, displacements did not violate deflection limiting volume in first period of simulation, the impact with the highest energy was absorbed properly. The von Misses stress field at time $0.0135 \mathrm{~s}$ in view on internal part is presented in Fig. 8.

In the next phase of simulation due to a gravity force, the weight hits the cab a few more times and then abandons structure in a safe way (Fig. 9).

\subsection{Local country FOPS codes}

In some particular cases of working conditions the requirements can be much more restricted. This situation exists for example in Poland, where structures for mining industry have to fulfil requirements of local codes close to the ISO one. The difference, for example in the case of FOPS test, is in the value of the impact energy. The Polish code PN-92/G-59001-"Rock Slide Protective Structures (RSPS). Requirements and tests" [14] require nearly six times higher impact energy $(E=60 \mathrm{~kJ})$. The first Author's research in the field of numerical simulations of protective structures has been conducted in accordance to this code [15]. The prototype of structure used actually in this paper was numerical 
tested firstly in accordance to maintained local country code requirements. Results of simulation conducted for the prototype of analysed structure shows that during the first impact displacements do not violate deflection limiting volume, but then due to the gravity force weight hits the cab a few more times and the structure fails. Cab's ceiling section is over stiffened and it causes the energy of the first impact is not absorbed properly. Fig. 10 shows displacements after the first impact in $\mathrm{Z}$ direction of exemplary node that may eventually violate deflection limiting volume. In addition, thickness of supporting tubes is too small. The failure of the structure is connected with the next impacts that destroys supporting tube section (Fig. 11). Fig. 12 presents plastic strain field after the damage.
Mentioned analysis expose the weakness of the structure and make suggestions how to modify it. Thickness of cab's sheet metal parts and tubes has been modified adequately. Modification causes the right response of cab on tested impact (Fig. 13). Simulations connected with PN92/G-59001 code with higher requirements in this case are presented in detail in [15].

The comparison between Fig. 10 and Fig. 13 shows that displacements caused by the first impact have higher values in case of modified structure. In other words, failed structure absorbs not enough energy during the first impact to ensure required safety. Fig. 14. shows displacement field connected with maximum deflection of cab's ceiling.

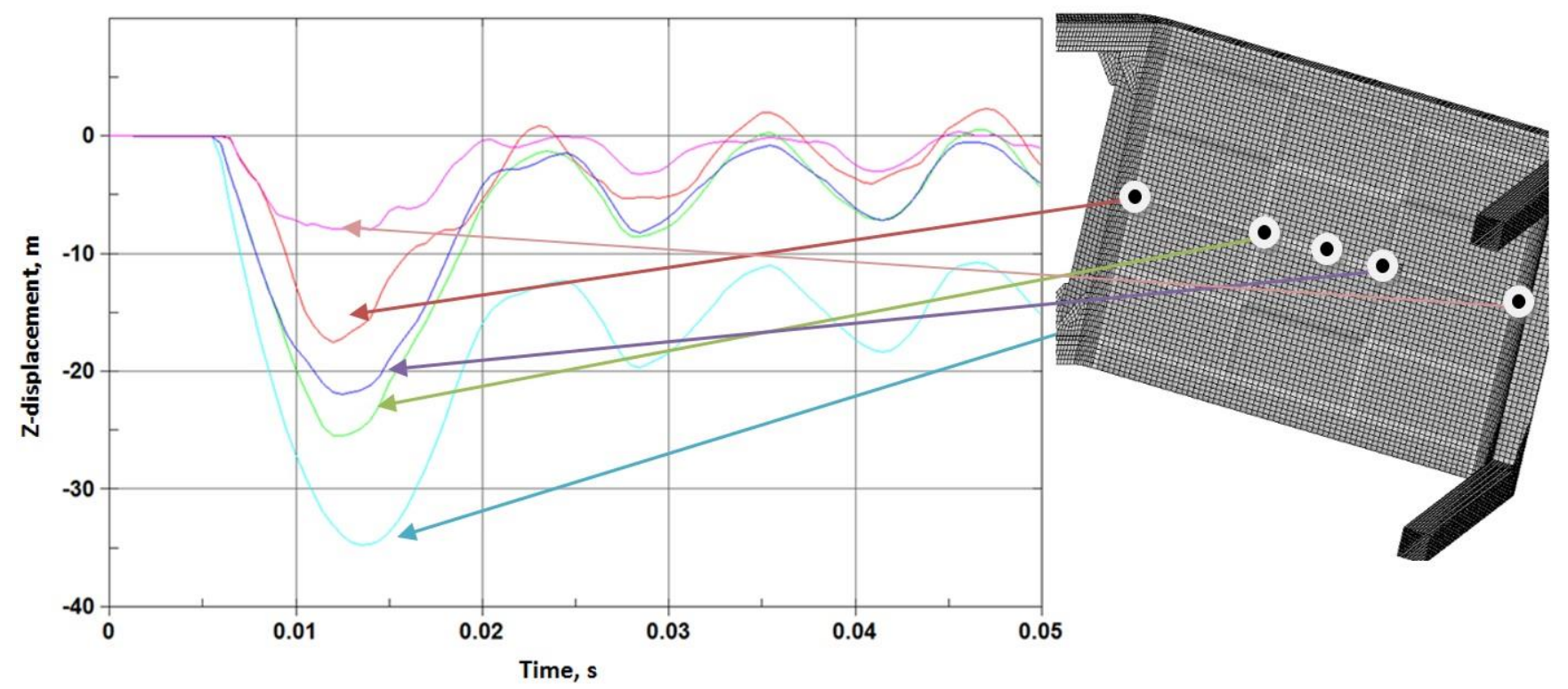

Fig. 7 Displacements of characteristic nodes in $\mathrm{Z}$ direction

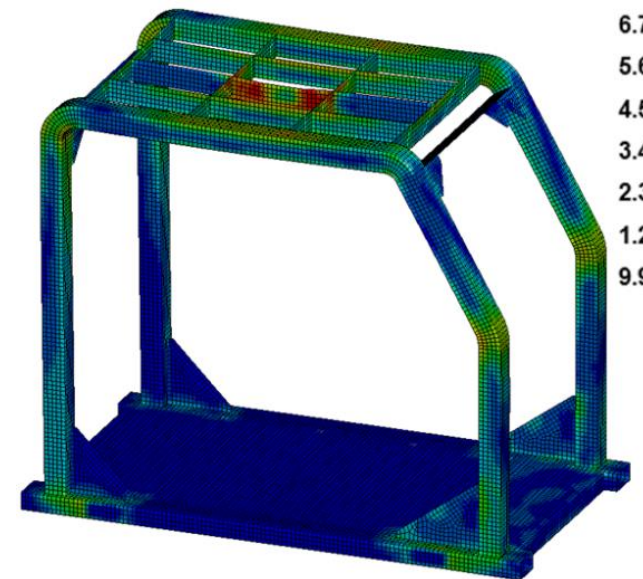

a

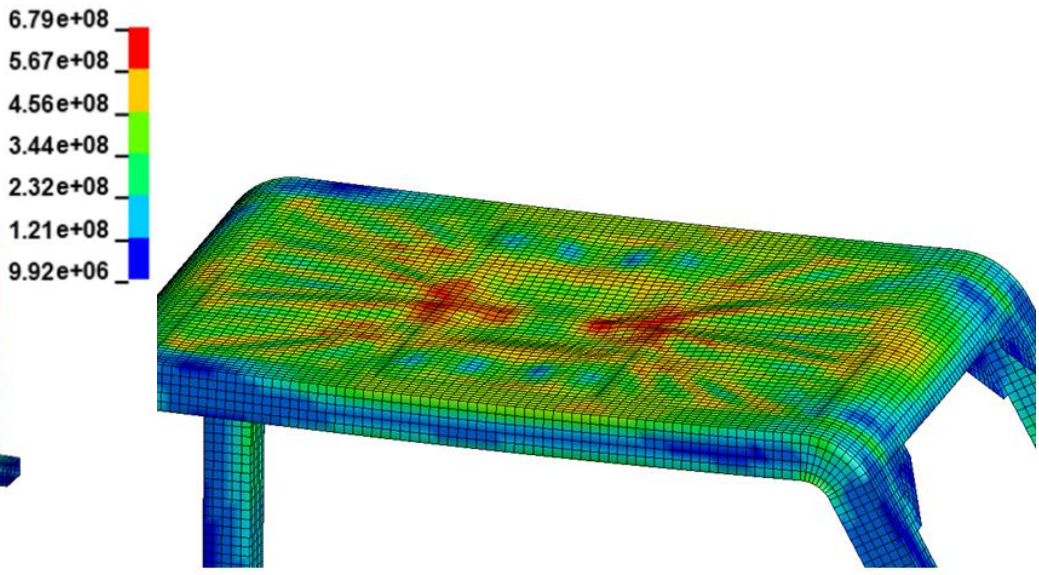

b

Fig. 8 Von Misses stress at time 0.0135, Pa: a) view without covering sheet metal b) detailed view on cab's ceiling

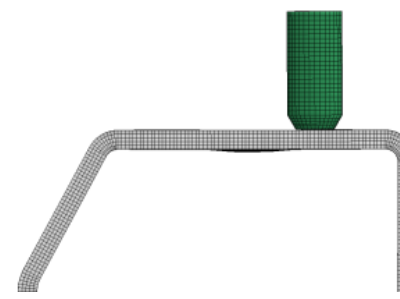

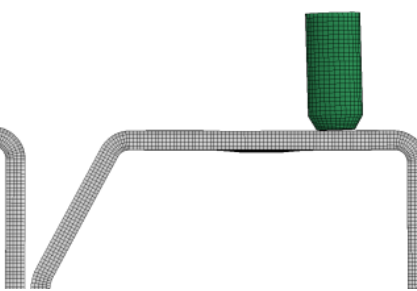

b

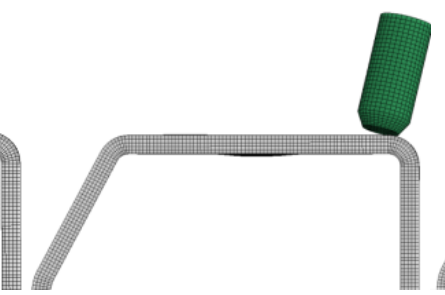

c

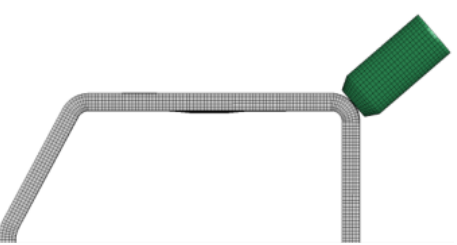

d

Fig. 9 Position of the falling object during simulation at time: a) $0.989 \mathrm{~s}$, b) $1.78 \mathrm{~s}, \mathrm{c}) 2.38 \mathrm{~s}$, d) $2.82 \mathrm{~s}$ 


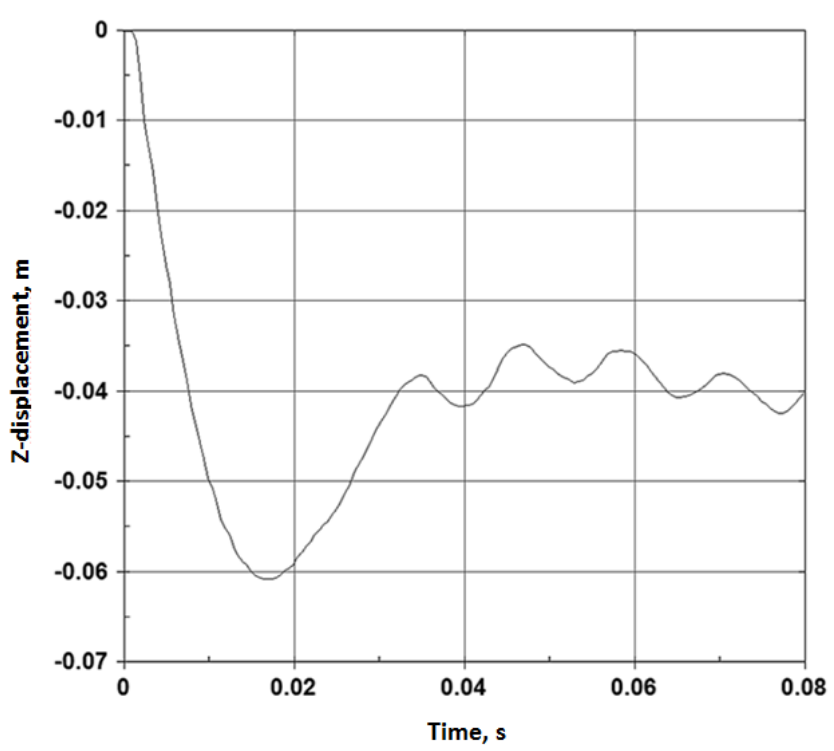

Fig. 10 Displacement of characteristic node of the prototype structure in $\mathrm{Z}$ direction

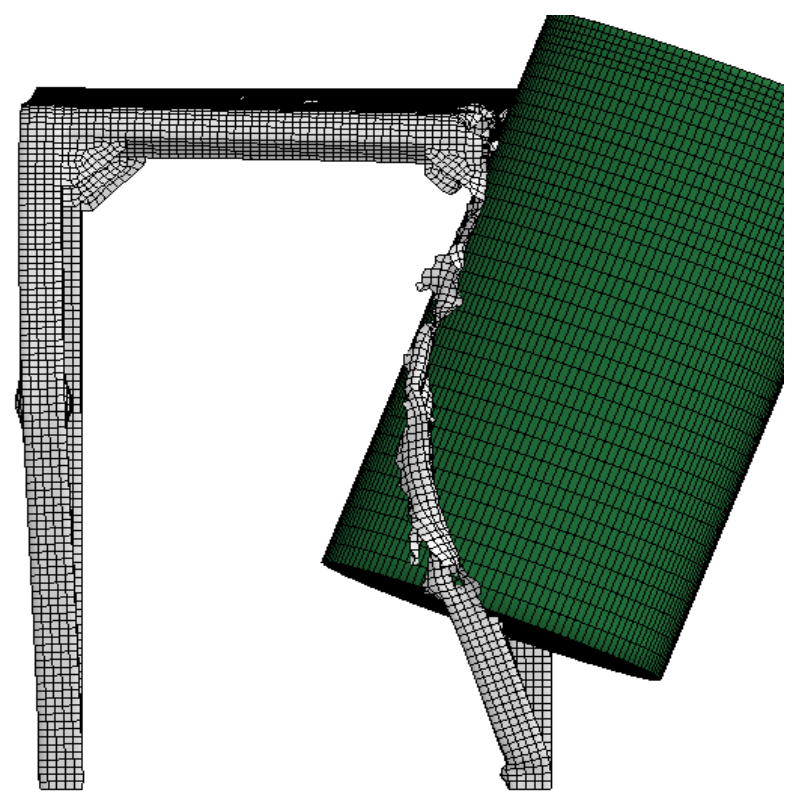

Fig. 11 Failure of the structure, position of weight after the damage

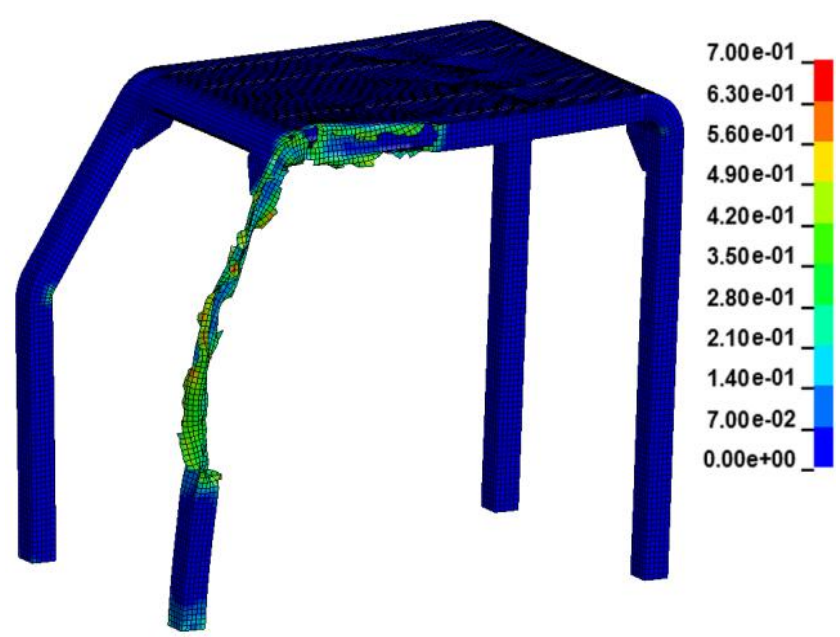

Fig. 12 Failure of structure- plastic strain after the damage

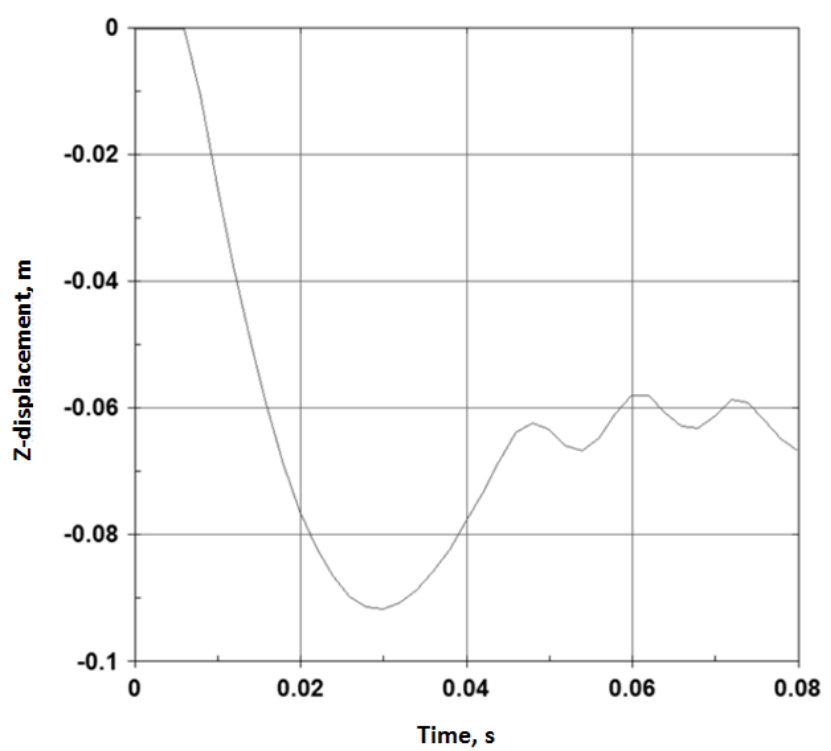

Fig. 13 Displacements of characteristic node of the modified structure in $\mathrm{Z}$ direction

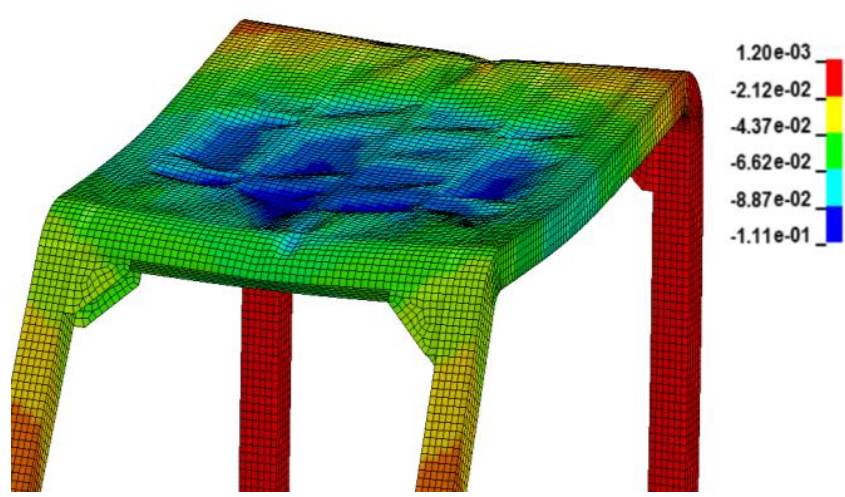

Fig. 14 Maximum deflection of the structure duringRSPS test simulation

\section{ROPS test simulation}

\subsection{Test overview}

Requirements of ROPS test are force resistance in the lateral, vertical and longitudinal directions (Fig. 15), and energy absorption in the lateral direction. In other words, lateral force has to reach required value and provide required energy, both conditions must be met to fulfil the code requirements.

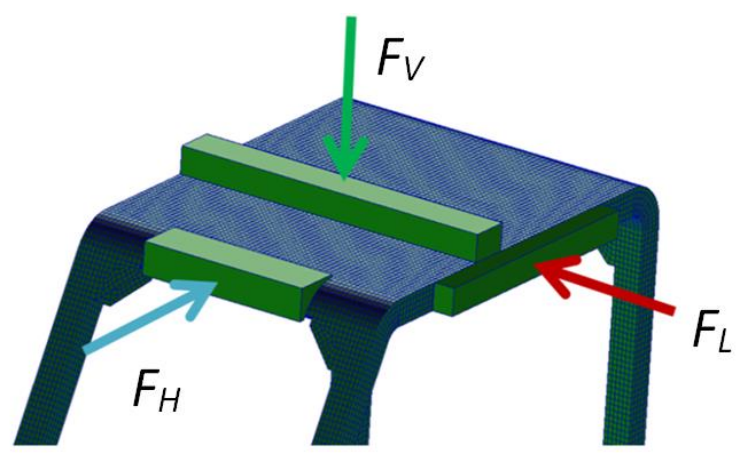

Fig. 15 Applied loads in the ROPS test

During the test loading is applied sequentially: lateral, vertical, and then longitudinal. Any interference in the 
structure during the test is not allowed. Codes specify forces and energy values depending on the machine type and mass.
Table 2 shows formulas that define values of force and energy in case of tracked earthmoving machinery.

Table 2

Forces and energy formulas for tracked earthmoving machinery for the following groups of machines: bulldozers, loaders, pipe layers and trenchers [3]

\begin{tabular}{|c|c|c|c|c|}
\hline Machine mass $m, \mathrm{~kg}$ & Lateral force $F_{L}, \mathrm{~N}$ & $\begin{array}{c}\text { Energy provided by the lateral } \\
\text { force } U, \mathrm{~J}\end{array}$ & Vertical load $F_{V}, \mathrm{~N}$ & Logitudinal load $F_{H}, \mathrm{~N}$ \\
\cline { 1 - 3 } $700<m \leq 4630$ & $6 m$ & $13000\left(\frac{m}{10000}\right)^{1.25}$ & \\
\cline { 1 - 3 } $4630<m \leq 59500$ & $70000\left(\frac{m}{10000}\right)^{1.2}$ & $13000\left(\frac{m}{10000}\right)^{1.25}$ & \multirow{2}{*}{$19.61 m$} & $4.8 m$ \\
\hline$m>59500$ & $10 m$ & $2.03 m$ & & $56000\left(\frac{m}{10000}\right)^{1.2}$ \\
\hline
\end{tabular}

Table 3 shows values taken into consideration during current numerical study (mass equals $8500 \mathrm{~kg}$ ). Similarly, to FOPS/RSPS tests, structure meets the requirements if the DLV space is not damaged during the test.

Table 3

Forces and energy values

\begin{tabular}{|l|l|}
\hline Lateral force $F_{L}, \mathrm{kN}$ & 57.6 \\
\hline Energy provided by lateral force, $\mathrm{kJ}$ & 10.61 \\
\hline Vertical force $F_{V}, \mathrm{kN}$ & 166.7 \\
\hline Longitudinal force $F_{H}, \mathrm{kN}$ & 46.1 \\
\hline
\end{tabular}

\subsection{Numerical procedure}

The finite element grid is the same as in FOPS/RSPS tests but fully integrated shell elements are taken into consideration. The numerical analysis does not take into account any transient events, loading has quasistatic characteristic. Generally, the analysis has got nonlinear static nature. Time in this analysis is essential to apply loads in proper order. In this case explicit integration is not efficient so implicit Newmark time integration scheme was applied [10]. The analysis is divided into two stages. The purpose of the first stage is to establish correlation between lateral force and provided energy. This approach is essential to apply lateral load in the second stage in the way that will meet force and energy conditions simultaneously. This analysis shows that minimum lateral force value, which is specified in code (Table 3), is not enough to satisfy energy condition. The second stage is the final simulation which consists of: lateral force that provides required energy (obtained from the first stage) and vertical and longitudinal forces. Material model is the same as in FOPS analysis but it does not consider strain rate effects.

\subsection{ROPS test - simulation results}

Fig. 16, a shows absorbed energy during lateral load, the important fact is that it reaches required value of $10.61 \mathrm{~kJ}$. Fig. 16, b shows maximum deflection of the structure under lateral load. DLV space is not affected by deflection during a whole simulation. Lateral load causes maximum stresses in the structure. Fig. 17 shows, in two views, Von Misses stresses. Fig. 18, a shows Von Misses stresses in view on internal part of cab's ceiling. Withstanding vertical and longitudinal loads proves that protective structure still has got appropriate stiffness despite plastic strain caused by lateral load (Fig. 18, b).

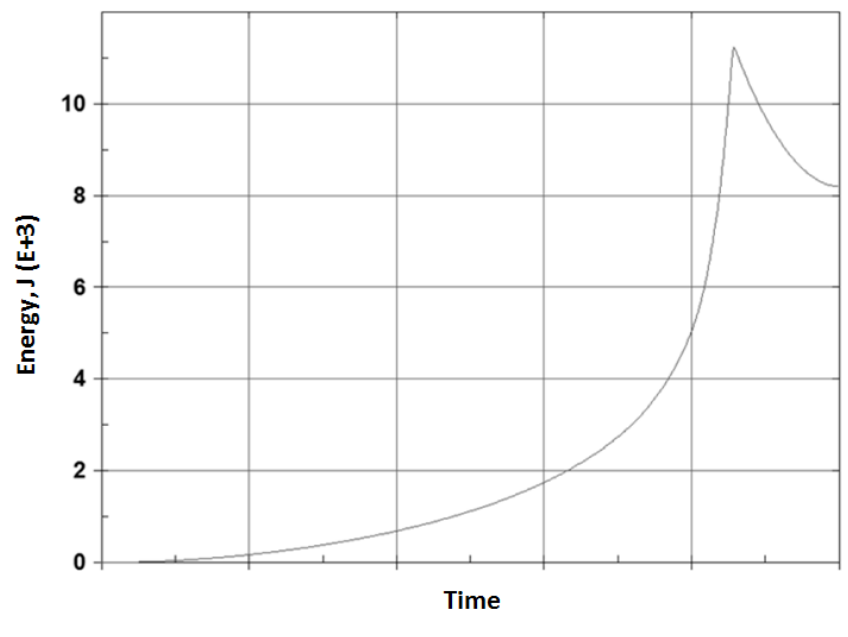

a

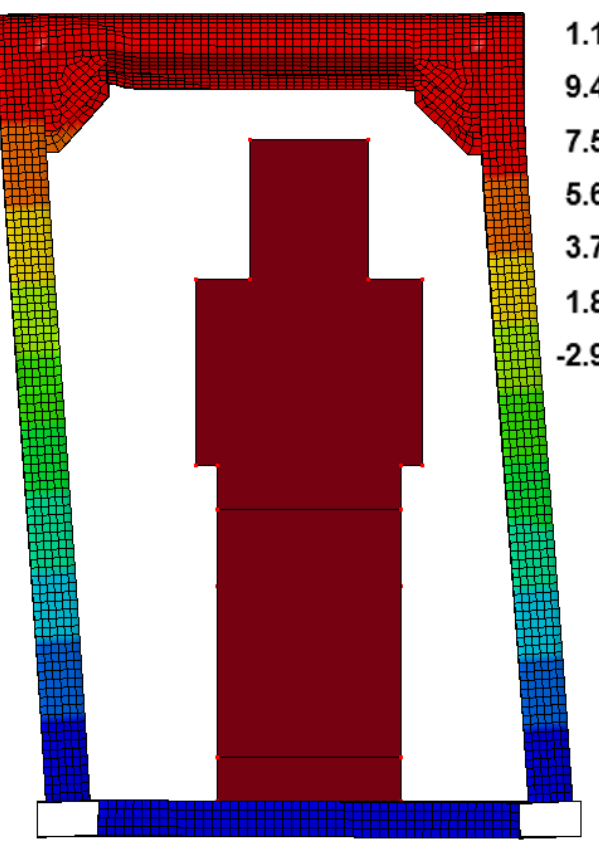

1.13 e- 01

$9.48 \mathrm{e}-02$

$7.58 \mathrm{e}-02$

5.67 e- 02

3.77 e- 02

1.87 e- 02

$-2.92 e-04$

$\mathrm{b}$

Fig. 16 Absorbed energy during lateral loading (a) and maximum displacements under lateral load, $\mathrm{m}(\mathrm{b})$ 


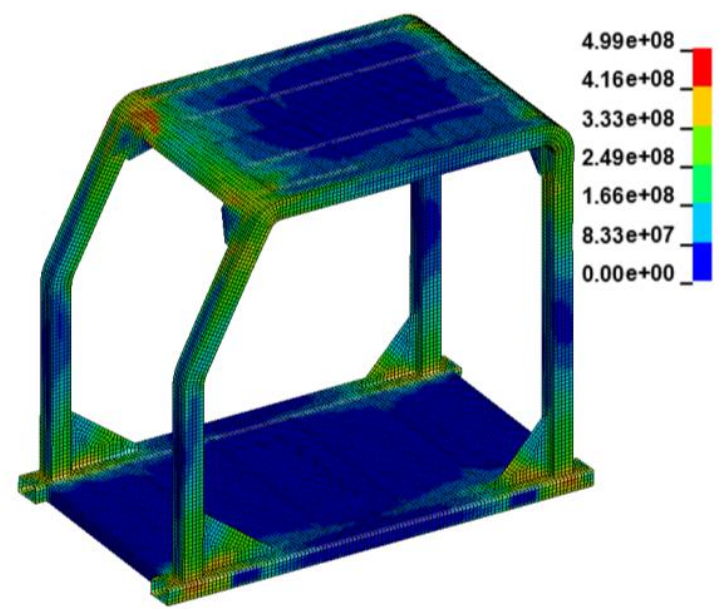

a

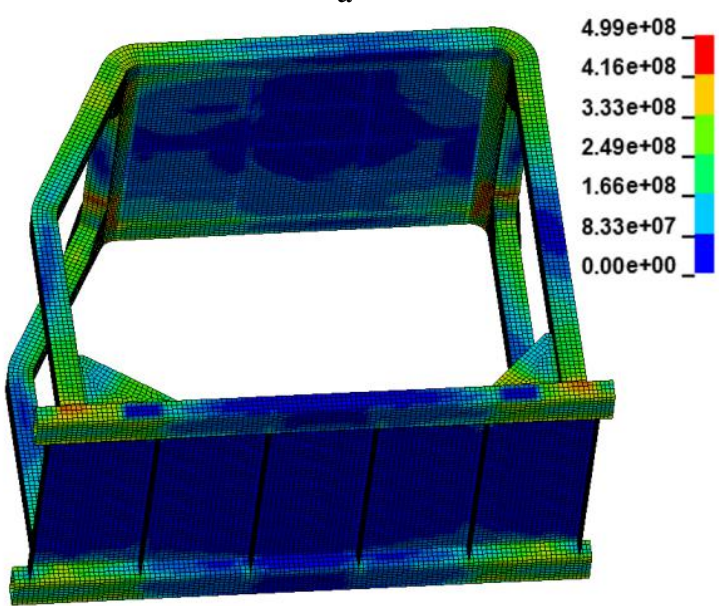

b

Fig. 17 a) Von Misses stresses under lateral load- view on the cab's top, $\mathrm{Pa}$; b) Von Misses stresses under lateral load - view on the cab's bottom, $\mathrm{Pa}$

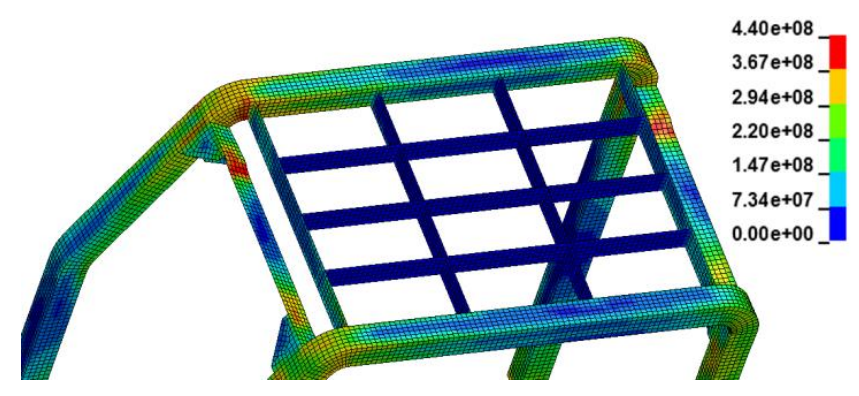

$\mathrm{a}$

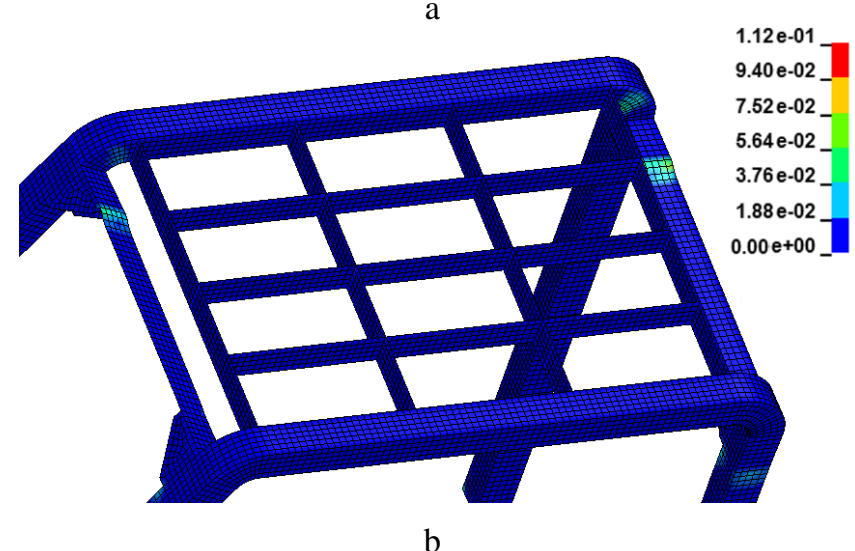

b

Fig. 18 a) von Misses stresses under lateral load, view on internal part, $\mathrm{Pa}$; b) plastic strain caused by lateral load

\section{Conclusions}

Numerical simulations of laboratory tests described in codes allowed to set up an adequate geometrical property of analyzed structure at stage of virtual prototyping. This approach may significantly reduce costs and time connected with experimental research while meeting the safety requirements. Additionally, presented methodology rises up the security of designing process and final structure. Numerical simulations allow to perform the test many times in opposite to experiment, where it can be done only once. Repeating the simulation is possible to pick up much more information about the structure taking into account the stochastic behaviour of dropped weight. Finite element model simplifications are set up on a safety side, so it is very likely that real structure could withstand even higher impacts than considered in boundary conditions. For example, in finite element model no energy dissipation was taken into consideration, all kinetic energy is converted directly into a strain energy. The simulation has not been limited to the analysis of the first impact but examined the behaviour of the structure during the whole test. It is essential because the structure's weakness is exposed at the end of the simulation. LS-DYNA is the software dedicated to simulate short-duration events so all analysis assumptions are easily implemented at the stage of building the finite element model.

\section{Acknowledgment}

The research presented in this paper was supported by the Silesian University of Technology Rector's Grant in the field of research and development No. 10/040/RGJ18/0065 and 10/040/RGJ19/0081.

\section{References}

1. Earth-Moving Machinery - Laboratory Evaluations of Protective Structures - Specifications for DeflectionLimiting Volume. ISO 3164.

2. Earth-Moving Machinery: Falling Object Protective Structures. Laboratory Tests and Performance Requirements. ISO 3449.

3. Earth-Moving Machinery: Roll-Over Protective Structures. Laboratory Tests and Performance Requirements. ISO 3471:2008.

4. Zienkiewicz, O. C. 2000. The finite element method, Fifth Edition, Butterworth-Heidemann.

5. Kaneda, S.; Tamagawa, T. 2003. Introduction of simulation of falling object protective structures, Komatsu Technical Report 49.

6. Karliński, J.; Rusiński, E.; Smolnicki, T. 2008. Protective structures for construction and mining machine operators, Automation in Construction 17: 232-244. https://doi.org/10.1016/j.autcon.2007.05.008.

7. Knight, N. Jr.; Jaunky, N.; Lawson, R.E.; Ambur, D.R. 2000. Penetration simulation for uncontained engine debris impact on fuselage-like panels using LS-DYNA, Finite Elements in Analysis and Design 36: 99-133. https://doi.org/10.1016/ S0168-874X(00)00011-1.

8. Ambur, D.R.; Jaunky, N.; Lawson, R.E.; Knight N. Jr. 2011 Numerical simulations for high-energy impact of thin plates, International Journal of Impact Engineering 25: 683-702. 
https://doi.org/10.1016/S0734-743X(00)00073-7.

9. Bathe, K.J. 1996. Finite Element Procedures., PrenticeHall. Inc.

10. Hallquist, J.O. 2009. LS-DYNA Theory Manual. Livermore: Livermore Software Technology Corp.

11. Ansys LS-Dyna User's Guide. Ansys Inc.

12. Cowper, G.R.; Symonds, P.S. 1958. Strain hardening and strain rate effects in the impact loading of cantilever beams," Brown University, Division of Applied Mechanics Report No. 28.

13. Johnson, G.R.; Cook, W.H. 1983. A constitutive model and data for metals subjected to large strains, high strain rate and high temperatures, Proceedings of the Seventh International Symposium on Ballistics, Hague, Netherlands, 541-547.

14. PN-92/G-59001. Self-propelled Mining Machines Rock Slide Protective Structures for Operator - Requirements and Tests.

15. Kokot, G.; Ogierman, W. 2013. The numerical simulation of a dynamic load acting on a protective cabin structure using LS-Dyna, Mechanika: Proccedings of 17th International Conference, Kaunas, 123-127.

\section{G. Kokot, W. Ogierman}

\section{THE NUMERICAL SIMULATION OF FOPS AND ROPS TESTS USING LS-DYNA}

S u m m a r y

This paper presents design process and numerical simulations of safety tests of the operator's protective structure of earth-moving machinery. It is connected with international code requirements according to design the protective structure of machines in the case of working environment with a danger of falling objects or situation of rolling-over. The discrete finite element numerical models and results of numerical simulation of codes required tests are presented. All finite element simulations were done using LS-DYNA software. The manufacturing process of earth-moving machinery is closely related to meeting the rigorous requirements of safety standards requiring a considerable number of difficult experimental studies. The calculation methodology presented in the article as well as the examples prove that the currently common numerical simulations allow to significantly reduce the number of experiments in the complex design process of heavy machinery and therefore significantly accelerate the implementation process as well as reduce the design and production costs.

Keywords: Falling Object Protective Structure (FOPS), Rollover Protective Structure (ROPS), drop test, protective structure, LS-DYNA. 